\title{
Going Offshore: Investments in German Wind Energy under Uncertainty
}

\author{
Yu-Fu Chen \\ Michael Funke
}

CESIFO WORKING PAPER NO. 5408
CATEGORY 10: ENERGy AND CLIMATE ECONOMICS
JunE 2015

An electronic version of the paper may be downloaded

- from the SSRN website:

- from the RePEc website:

- from the CESifo website:

WwW.SSRN.com

Www.RePEc.org

www.CESifo-group.org/wp 


\title{
Going Offshore: Investments in German Wind Energy under Uncertainty
}

\begin{abstract}
Employing a continuous-time real options modeling framework, this paper scrutinizes the incentives to invest in German offshore wind farms. The focus of the analysis is the mode of action of the German feed-in tariff system for offshore wind energy deployment. The numerical results reveal that the long term subsidies in Germany set prices that provide higher returns than needed to secure investment, even when taking the uncertainties involved into account. The results obtained can be used by policy-makers to design comprehensive and efficient offshore wind energy support measures.
\end{abstract}

JEL-Code: C610, D920, E220, H230, O330.

Keywords: real options, offshore wind energy, feed-in tariff, tender bidding, Germany.

\author{
Yu-Fu Chen \\ University of Dundee \\ Economic Studies, School of Business \\ 3 Perth Rd \\ United Kingdom - Dundee DD1 4HN \\ y.f.chen@dundee.ac.uk
}

\author{
Michael Funke \\ Hamburg University \\ Department of Economics \\ Von-Melle-Park 5 \\ Germany - 20146 Hamburg \\ michael.funke@uni-hamburg.de
}

Dundee and Hamburg, June 2015

The authors acknowledge partial funding from Hamburg University's Cluster of Excellence "Integrated Climate System Analysis and Prediction" (CliSAP) which is funded by the German Research Foundation (Deutsche Forschungsgemeinschaft). 


\section{Introduction}

Wind energy constitutes the fastest-growing segment of green energy worldwide due to abundant and reliable wind resources. Offshore wind, unlike its more familiar onshore counterpart, is a relatively new form of renewable energy that has only recently spread beyond Europe to China and a handful of other countries. By December 31, 2014, 258 offshore wind turbines in the German North Sea and Baltic Sea with a total capacity of 1,049.2 megawatts (MW), fed-in-to the grid. In the year 2014, 142 offshore wind turbines with a cumulative capacity of 528.9 MW, were newly connected and started feeding into the grid. The cumulated capacity of the 285 offshore turbines installed by the end of 2014 but not hooked up to the grid amounts to 1,303.1 MW. Another 220 foundations are currently under construction and further projects are in the pipeline. Such pronounced trends tend to focus our mind.

Up to the present day, most offshore wind farms have been installed in shallow waters just off the coast and locations have been largely dictated by the shallowness of the sea bottom and the vicinity to developed electricity markets. In the future, however, new technologies will push the depth threshold further and there are plans for deep-water wind farms along several stretches of Germany's coastline. This envisaged expansion plan apparently creates enormous technological challenges. ${ }^{1}$ In particular, the necessary electrical offshore grids have to be installed to overcome the subsea cable transmission constraints. Furthermore, various other human- and nature-related non-wind uses of the Baltic and North Sea basin have to be taken into account (Jongbloed et al., 2014). A comprehensive overview of the main economic issues associated with investments in offshore wind parks is provided by Green and Vasilakos (2011).

The offshore wind construction schedule is part of Germany's roadmap for renewable deployment (Energiewende), which aims to redesign Germany’s energy system within the next few decades. This flagship project includes ambitious conservation and efficiency goals, but above all it involves changing the power supply. By 2022, all nuclear power plants are to be switched off. At the behest of emotion, a decision to favor any energy source over nuclear was made. In addition, by 2050 about 80 percent of electricity is to come from renewable sources, compared with 22 percent now. Furthermore, $\mathrm{CO}_{2}$ emissions are supposed to fall from those in 1990 by 50 percent in 2030 and 80 percent by 2050. In principle, the Energiewende may bring opportunities for German industry to become a global leader in tomorrow's energy-efficient and green technologies. ${ }^{2}$

The original German nuclear phase-out policy, which is no longer relevant, was set in the early 2000s, when the Green Party was the junior partner in a coalition with the SPD under Chancellor Gerhard

\footnotetext{
${ }^{1}$ The deep offshore environment starts at water depths greater than $50 \mathrm{~m}$. For the technological challenges of deep-water wind farms, see http://www.ewea.org/fileadmin/files/library/publications/reports/Deep_Water.pdf.

${ }^{2}$ One should bear in mind that the success of a policy should not be measured in terms of the amount of offshore wind capacity installed, but in terms of efficient implementation. A consequence of the success of the Energiewende is that even modern and highly efficient gas-fired power plants are no longer profitable to operate.
} 
Schröder. Nuclear power plants were destined to be switched off by 2022. At the same time, the Renewable Energy Sources Act (Erneuerbare Energien Gesetz - EEG) promised 20 years of guaranteed prices and priority access to the power grid for anyone who installed wind, solar or other renewable sources. In other words, to promote the deployment of onshore and offshore wind turbines, solar panels and electricity storage, investors will receive an attractive, long-term feed-in price for the electricity that they produce. These policies aimed at internalizing the technological externalities in learning technologies, such as renewables, and pursued the objective of bringing investments closer to the social optimum. The feed-in tariffs are often seen as a necessary lever to set renewable energy in motion. $^{3}$

The next energy policy U-turn occurred after the Fukushima Daiichi nuclear power plant disaster in March 2011 which boosted the debate on nuclear energy. In the aftermath of Japan's nuclear disaster Chancellor Merkel decided that Germany would abandon nuclear power after all. The eight oldest nuclear power plants were switched off immediately, and the rest will be shut down by 2022. One of the most ambitious elements of the Energiewende is to build 6.500 MW of wind turbines off the North Sea and Baltic Sea coasts by 2020. There are several reasons for the rush to offshore wind energy. One is the opportunity to circumvent anti-onshore wind farm protests. Politically onshore wind farms are more controversial as people object to their size and the noise of their blades. On the contrary, there are few visual or environmental restraints on the size of offshore wind farms. Furthermore, offshore wind farms offer much higher energy yields, as the power output is theoretically a function of the cube of the higher and steadier offshore wind speed. However, these potential gains of capturing economies of scale are counterbalanced by higher investment and maintenance expenditures. Finally, the offshore wind technology offers prospects of renewable industry development, job creation and technology leadership. However, it must be said that the expansion of offshore wind energy has outstripped the ability to develop the necessary electricity grid and storage infrastructure to support it. The reason is that it has proved politically difficult to pass through the regulatory hoops to build transmission grid lines from the North Sea wind hotspot to the demand centers in southern and western Germany, not least because policymakers play to their particular audiences. ${ }^{4}$

With this background in mind, we analyze the investment in a German offshore wind farm bearing in mind the specific German support policy framework through the prism of a real options modelling

\footnotetext{
${ }^{3}$ Given the characteristics of the energy system (path dependency, lock-in effects), front-loaded feed-in tariffs have become the mainstream way to push the large-scale deployment of renewable energy in the EU [see Kitzing et al. (2012)]. For the theoretical case in favor of using industrial policy to facilitate green growth, see Rodrik (2014). Acemoglu et al. (2014) developed an endogenous growth model in which clean and dirty technologies compete in production and innovation. If dirty technologies are more advanced to start with, the potential transition to clean technology requires subsidies.

${ }^{4}$ The Energiewende has turned out to be rockier than expected. The transition towards renewables has upset the building of new conventional gas power plants, which are much cleaner but burn more coal. As a result, the baseload electricity production from brown coal (lignite), the least efficient and dirtiest sort, reached its highest level since 1990 in the year 2013. In effect, the energy turn has so far increased anthropogenic $\mathrm{CO}_{2}$ emissions.
} 
framework. The remainder of this paper is organized as follows. Section 2 introduces the multi-stage modeling framework and highlights the advancement and value added of this research with respect to the related literature. We successively model the investment incentives of two possible subsidy arrangements: (i) the EEG feed-in tariff system, and (ii) a possible future tender bidding system. ${ }^{5}$ We also present efficient solution methods for solving this class of models to make them really useful for policymaking. Section 3 provides model calibrations illustrating the theoretical modelling approaches. Section 4 draws conclusions and hints at future research. Finally, the Appendix offers the remaining proofs and further details of the numerical solution techniques for the optimal stopping problem.

\section{The Analytical Framework}

The starting point for the analysis in this paper is the literature on investment decisions under uncertainty, which has highlighted the effects of irreversibility in generating real options. In these models, the interplay between uncertainty and irreversibility leads to a range of inaction whereby firms prefer to "wait and see" rather than undertaking a costly investment decision with uncertain consequences. ${ }^{6}$ The general idea underpinning the view that offshore investment decisions are optionrights is that renewable energy investments can be seen as analogous in nature to the purchase of a financial call option, in which the investor pays a premium price to obtain the right to buy an asset for some time at a predetermined price (exercise price) that is eventually different from the spot market price of the asset. In this analogy, the investor, through his/her investment decision, pays a price that gives him/her the right to invest, now or in the future, in return for revenues. Taking into account this options-based approach, the calculus of suitability cannot be performed simply by applying the net present value rule, but rather has to consider the following three salient characteristics of the investment decision: (i) there is uncertainty about future electricity price fluctuations and uncertainty about declining sunk costs over time and thus there is (partial) uncertainty about future payoffs; (ii) waiting allows investors to gather new information on uncertain future electricity prices, the yet-tobe-proven technologies involved and the induced technological progress; and (iii) the investment expenditures are partially or completely irreversible. ${ }^{7}$ These characteristics are encapsulated in the concept of real options models. Like Boomsma et al. (2012), we assume that although the allotment of a license to build a wind farm is for a fixed number of years, the option to defer is perpetual. Below

\footnotetext{
${ }^{5}$ The stepwise procedure for developing our models makes sure that we account for regime-specific characteristics.

${ }^{6}$ Almost all the existing analyses of the EEG employ the simpler net present value rule [see, for example, Balks and Breloh (2014a, 2014b) and Prässler and Schaechterle (2012)]. Ignoring the interaction between uncertainty and irreversibility risks overlooking some important factors in offshore technology diffusion. In the remainder of this article, we avoid discussions of the merits and drawbacks of the real options approach and instead focus on how researchers and business practitioners can implement such a model if they deem it to be desirable and useful for strategic investment decision making in the specific offshore wind context.

${ }^{7}$ Finance has traditionally emphasized the role of quantifiable risk. In this paper, risk, which is understood to be measurable, and uncertainty, which is not, are used interchangeably.
} 
we frame the investment decision in customized real options frameworks that factor the above characteristics into the investment decision. ${ }^{8}$

\subsection{The Investment Incentives of the EEG Feed-In Tariff System}

To start, we survey the German feed-in tariffs for offshore wind energy aimed at making offshore wind competitive against conventional power plants. The EEG 2012 aimed to increase the share of renewable energy significantly within the next decades. To this end, the EEG 2012 regulated the remuneration of power from regenerative energy plants in the various sectors including offshore wind farms. In the EEG 2012, the power that is produced is entitled to fixed above-market premium feed-in tariffs over longer periods, meaning that the operator receives a pre-determined fixed number of cents (ct) per kilowatt hour (kWh). Feed-in tariffs are differentiated by technology to outweigh technologyspecific cost disadvantages compared with conventional power generation based on coal, gas or nuclear fuels. They are based on the market price topped up by a premium payment. These contractual prices are levied on electricity bills and the cost is thus borne by German consumers.

Offshore wind farms receive an initial remuneration of $15 \mathrm{ct} / \mathrm{kWh}$ for a period of 12 years. As an additional option the so-called acceleration model ("Stauchungsmodell”) was included in the EEG 2012. With this front-loaded model, the operating company has the opportunity to receive initial remuneration of $19 \mathrm{ct} / \mathrm{kWh}$ for a shortened period of 8 years, provided that the wind farm is put into operation before 2018. In other words, the acceleration model intends to bring forward project revenues to earlier years. Furthermore, for projects that are at least 12 nautical miles away from the coast and/or in water deeper than 20 meters, the period for the increased initial remuneration is extended depending on the actual site conditions. Strictly speaking, the period during which the increased initial remuneration of $15 \mathrm{ct} / \mathrm{kWh}$ is paid is extended by 0.5 months for each nautical mile exceeding 12 nautical miles that the deep-water wind farm is from the coast and by 1.7 months for each full meter of water depth beyond 20 meters. ${ }^{9}$ This special regulation also applies to wind farms of which the operators voted for the higher remuneration rate of $19 \mathrm{ct} / \mathrm{kWh}$ for a period of 8 years in line with the acceleration model. Under these circumstances, the remuneration of $15 \mathrm{ct} / \mathrm{kWh}$ is only due for the extension period. Afterwards, a lower bound flat rate of $3.5 \mathrm{ct} / \mathrm{kWh}$ is guaranteed until the end of the subsidy period of 20 years. The market electricity prices are applied for the remaining 5

\footnotetext{
${ }^{8}$ The real options literature so far has not adopted such an encompassing view, but several elements have already been developed. Indeed, extensive literature exists on investment under uncertainty, and we naturally build on it. For example, Dixit and Pindyck (1994) and Stokey (2009) provided textbook treatments of the real options workhorse models as well as illuminating taxonomies of the literature. Boomsma et al. (2012) provided an onshore wind power case study for Norway employing a real options framework. Another early example is Hlouskova et al. (2005). However, none of the papers consider the specific design of the German EEG feed-in support system for offshore wind energy.

${ }^{9}$ For the estimated impact of depth and distance from the coast upon offshore wind energy costs, see Green and Vasilakos (2011), Table 2, p. 498 and Prässler and Schaechterle (2012), Appendices B1 and B2.
} 
years, until the offshore wind farm is completely written off. The graphical illustration in Figure 1 clarifies the assumed timeline of the multi-stage fixed feed-in tariff scheme.

Figure 1: Timeline of the Multi-Stage Offshore Wind Energy Feed-in Tariff Scheme

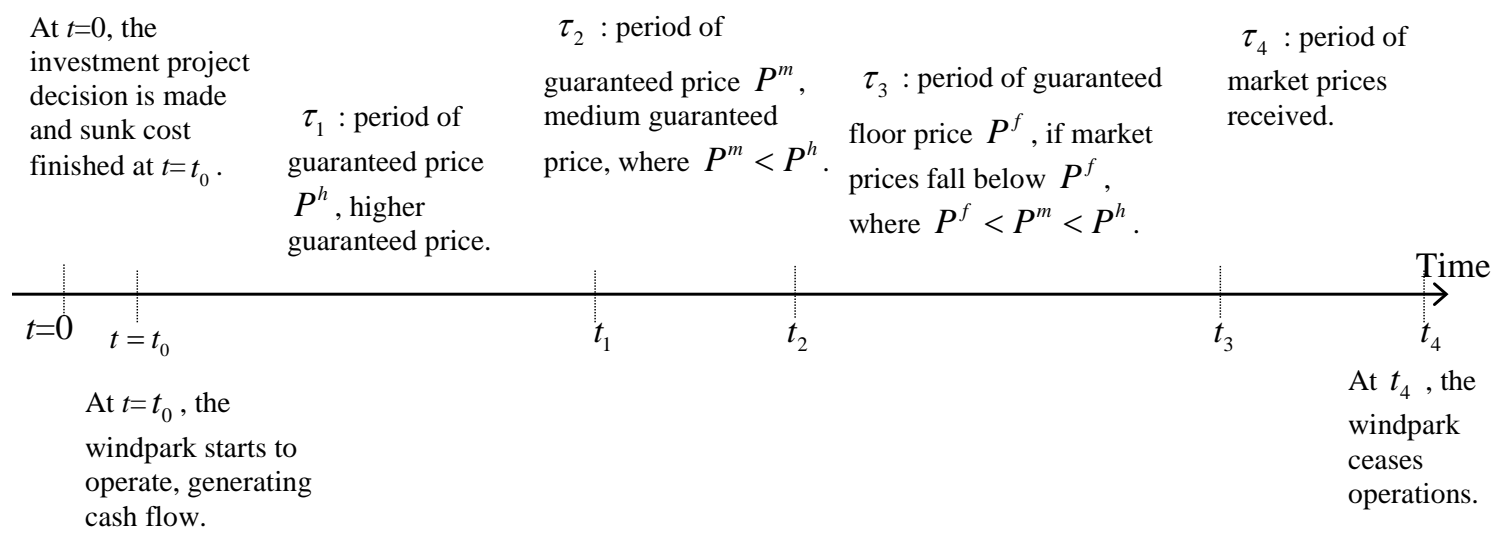

Which incentives emerge from these measures for optimizing investors? The main contribution of this paper is to present a tractable model of the various elements of the EEG 2012 feed-in tariff system in a real options framework. Modeling the German EEG 2012 support scheme entails tackling the very special policy design of time-limited flat feed-in tariffs in combination with a time-limited stochastic feed-in tariff with a guaranteed lower bound. As shown in Figure 1, the investment decision is made at $t=0$, while the wind farm is put into operation and the associated sunk costs are realized at $t=t_{0}$. Period 1 lasts from $t=t_{0}$ (the initial commissioning date) to $t=t_{1}$, where $\tau_{1} \in\left(t_{1}, t_{0}\right)$. During period $\tau_{1}$, the offshore wind farm is guaranteed a fixed electricity price $P^{h}=19 \mathrm{ct} / \mathrm{kWh}$. In the second operating phase, $\tau_{2} \in\left(t_{2}, t_{1}\right)$, the electricity price is guaranteed at $P^{m}=15 \mathrm{ct} / \mathrm{kWh}$. In the third operating phase, $\tau_{3} \in\left(t_{3}, t_{2}\right)$, the wind farm is guaranteed a floor price, $P_{f}$, if the electricity market price, $P_{t}$, falls below $P_{f}=3.5 \mathrm{ct} / \mathrm{KWh}$. Accordingly, the actual received prices for the wind farm are equal to $\max \left(P_{f}, P_{t}\right)$. In other words, the operating company receives the electricity market price, $P_{t}$, if $P_{t}>P_{f}$. Conversely, for $P_{t} \leq P_{f}$, the operating company receives the electricity floor price, $P_{f}$. Summing up the above, the electricity prices received over the three operating phases are deterministic in periods $\tau_{1}$ and $\tau_{2}$ and stochastic in period $\tau_{3}$, as shown in Figure 2 . In the fourth operation phase $\tau_{4} \in\left(t_{3}, t_{4}\right)$ the offshore wind farm operators receive the future market prices of electricity. In other words, the project fully bears the electricity spot price risk. 
Figure 2: Electricity Prices Received in the Three Operating Phases

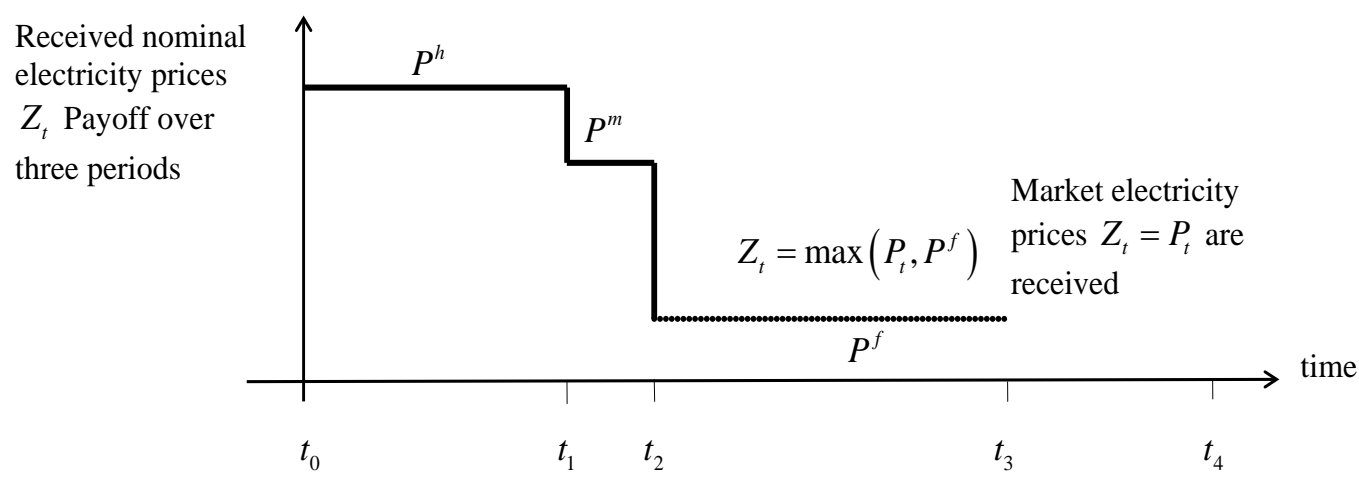

We now turn to a description of our customized continuous-time stochastic model in which the interplay between these various factors is formally analyzed. We assume that the wholesale electricity prices follow the mean-reverting stochastic process:

$$
d \ln P_{t}=\kappa\left(\ln \bar{P}_{t}-\ln P_{t}\right) d t+\sigma d W_{t}
$$

where $P$ is the nominal electricity prices, $\bar{P}$ denotes the long-term constant prices, $\kappa$ is the parameter related to the mean-reverting speed of electricity prices returning to long-run equilibrium $\bar{P}$ and $\sigma$ is the volatility parameter of the standard Wiener process $W$. Producer (wholesale) electricity spot and forward trading now takes place to a large extent on exchanges such as the European Energy Exchange (EEX) in Leipzig (see https://www.eex.com/de/). Therefore we assume that upon expiry of the fixed feed-in tariffs, production is sold on the spot market and the project fully bears the spot price risk. The day-ahead spot market prices for electricity fluctuate considerably. These short-term price changes are attributable primarily to the varying demand and increasingly to the variation in wind and photovoltaic power generation. Beyond the short-run volatility, increasing power generation from renewable energy has resulted in constant wholesale electricity prices over the last decade. Thus, the mean-reverting stochastic process is a suitable modeling approach. ${ }^{10}$

The investor's problem is to maximize the discounted value of profit for the firm, $V^{E E G}$, which is given by

$$
V^{E E G}=(1-\tau) E_{0}\left[\int_{t_{0}}^{t_{4}} Z_{t}(a \bar{y}-\delta \bar{y}) e^{-r\left(t-t_{0}\right)} d t\right],
$$

\footnotetext{
${ }^{10}$ Schwartz and Smith (2000) studied the properties of commodity spot price processes and suggested that shortterm variations in these prices are mean-reverting. Cartea and Figueroa (2005) presented a mean-reverting model for the electricity spot price and derived the corresponding forward price in closed form.
} 
where $E_{0}[\cdot]$ is the expectation operator based on the information available at $t=t_{0}, \tau$ is the constant tax rate on profits, $Z_{t}(a \bar{y}-\delta \bar{y}), Z_{t}$ is the electricity price received in various phases, $\bar{y}$ is the maximum wind farm electricity output capacity per year, $a$ is the capacity utilization rate, $\delta$ is the constant annual maintenance or operational cost rate per maximal output and $r$ is the discount rate. Pulling the deterministic parts out of the integral, equation (2) simplifies to

$$
\begin{aligned}
V^{E E G}=A_{0}+ & B_{0}+(1-\tau) E_{0}\left[\int_{t_{2}}^{t_{3}}\left[\max \left(P_{t}, P^{f}\right) a \bar{y}-\delta \bar{y}\right] e^{-r\left(t-t_{0}\right)} d t\right] \\
& +(1-\tau) E_{0}\left[\int_{t_{3}}^{t_{4}}\left[P_{t} a \bar{y}-\delta \bar{y}\right] e^{-(r+\lambda)\left(t-t_{0}\right)} d t\right]
\end{aligned}
$$

where

$$
A_{0}=(1-\tau) \int_{t_{0}}^{t_{1}}\left(P^{h} a \bar{y}-\delta \bar{y}\right) e^{-r\left(t-t_{0}\right)} d t=\frac{(1-\tau)\left(P^{h} a \bar{y}-\delta \bar{y}\right)\left(1-e^{-(r+\lambda)\left(t_{1}-t_{0}\right)}\right)}{r+\lambda}
$$

and

$$
\begin{aligned}
B_{0}=(1-\tau) \int_{t_{1}}^{t_{2}}\left(P^{m} a \bar{y}-\delta \bar{y}\right) e^{-r\left(t-t_{0}\right)} d t \\
=\frac{(1-\tau)\left(P^{m} a \bar{y}-\delta \bar{y}\right)\left(e^{-(r+\lambda)\left(t_{1}-t_{0}\right)}-e^{-(r+\lambda)\left(t_{2}-t_{0}\right)}\right)}{r+\lambda} .
\end{aligned}
$$

As shown in the Appendix, approximate analytical solutions for period 3 and period 4 can be obtained by numerical integration. After obtaining the intertemporal value for the whole life of the offshore wind farm, we need to turn our attention to the real options and real sunk costs.

The real options are only related to the uncertain part of the intertemporal value of equation (3). Note that the duration $\tau_{3}$ of the third operating phase starts from $t=t_{2}$ and lasts until $t_{3}$. This means that we need to determine the real options values at $t=t_{2}$ and then reverse compute the value of the real options at $t=t_{0}$. The value-matching condition for the offshore wind farm at $t=t_{0}$ is denoted by

$$
V^{E E G}=E_{0}[\operatorname{sunk} \text { cost }]+\text { real options }\left(\max \left(P_{t}\left(t ; \tau_{3}\right), P^{f}\right), P_{t}\left(t ; \tau_{4}\right) \text {, sunk cost uncertainty }\right)
$$


where $V^{E E G}$ is denoted by equation (3). Value-matching implies that offshore investment is undertaken when the value of the project equals the option value, that is, when the value of waiting is zero. Note that due to the mean-reverting character of electricity prices with high mean-reversion rates, only the sunk costs' uncertainty exerts an influence upon the real options. For details, see the Appendix. In other words, we assume that real options are only a function of sunk cost uncertainty:

$$
F(\text { sunk cost uncertainty })=\text { real options } \equiv \text { real options(sunk cost uncertainty) }
$$

Finally, it needs to be borne in mind that offshore wind technology is still in its infancy. A recent study by Prognos AG and the Fichtner Group invoked the argument that costs will fall greatly if the infant offshore wind farm technology is deployed on a large scale. In particular, the cost of electricity from offshore wind farms can be reduced by about one-third until 2023. ${ }^{11}$ The main driver of the cost reduction is learning-by-doing technological development across the entire supply chain. Particularly regarding investment costs, substantial savings can be achieved. The costs for support structures and other components as well as for the installation will also decline. A straightforward functional form for such declining sunk costs due to learning by doing and experimentation is $E_{0}$ [sunk cost] $=C_{0}+$ $E_{0}\left[C_{1}\right] e^{-h t}$, where $C_{0}$ denotes the sunk cost of the sophisticated state-of-the-art technology and $E_{0}\left[C_{1}\right] e^{-h t}$ represents the declining variable sunk costs over time with uncertain $C_{1}$ and $h>0$ determines the cost reduction over time. The implication of sunk cost uncertainty is that although it seems counterintuitive to delay offshore wind energy investment decisions in the light of expected lower subsidies in the future, it may be perfectly rational from the point of view of the investor. The intuition behind the surprising result is that due to the surge in aggregate offshore wind farms, the investment costs fall over time. This makes future investment more attractive and may offset the investment-depressing effect of lower subsidies in the future. One may interpret this as a "perverse" effect, whereby the expected technological progress undermines the effectiveness of the Energiewende. To address this issue, we specifically incorporate learning-by-doing effects into our model.

For mathematical tractability, and without loss of generality, we assume that $C_{1}$ follows a standard geometrical Brownian motion without trend satisfying the usual conditions. More precisely, we assume

$$
\text { sunk cost }=C_{0}+X_{t} \text {, }
$$

where $X_{t}$ follows a geometrical Brownian motion with a negative trend. Thus, $X_{t}$ is governed by

${ }^{11}$ Available at http://www.offshore-stiftung.de/node/76. 


$$
d X=-h X d t+\sigma_{X} X d W^{x}
$$

where $\sigma_{X}$ is the uncertainty parameter for stochastic process $X$ and $W^{x}$ is the standard Wiener process for $X$. We assume that the stochastic process for future costs is independent of the stochastic process for the electricity spot prices in equation (1). According to Bellmann's principle and Ito's lemma, $F(X)$ must satisfy the second-order differential equation

$$
r_{X} F=-h X F_{X}+\frac{1}{2} \sigma_{X}^{2} X^{2} F_{X X}
$$

where $r_{X}$ is the required rate of return of sunk cost risk. As shown in the appendix, due to the meanreverting character of electricity prices, uncertain future electricity prices have a negligible impact upon real options. Thus, we use a different discount rate, $r_{X}$, for the more timely sunk cost uncertainty. Furthermore, we employ a dynamic programming type of real options instead of the contingency claim one. Assuming that there is no opt-out option for the wind farm owners, the solution is given as

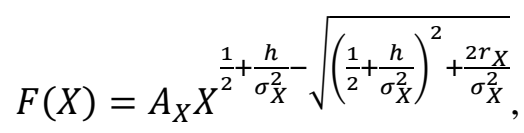

where $A_{X}$ is an unknown parameter to be determined by the smooth-pasting condition, and the term $\left(\frac{1}{2}+\frac{h}{\sigma_{X}^{2}}-\sqrt{\left(\frac{1}{2}+\frac{h}{\sigma_{X}^{2}}\right)^{2}+\frac{2 r_{X}}{\sigma_{X}^{2}}}\right)$ represents the negative root of the characteristic equation derived from equation (10). Substituting the analytical solutions for real options back into the value-matching condition, we obtain the following value-matching condition and its corresponding smooth-pasting condition:

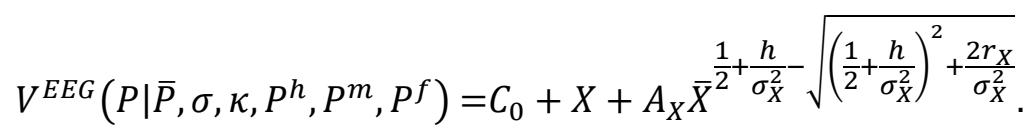

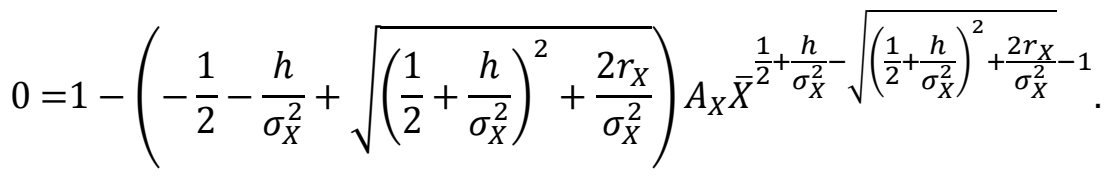

Note that $V^{E E G}$ denotes the total expected intertemporal payoffs of the offshore wind farm. The associated threshold of $X, \bar{X}$, for undertaking the offshore wind farm investment is 


$$
V^{E E G}\left(P \mid \bar{P}, \sigma, \kappa, P^{h}, P^{m}, P^{f}\right)=C_{0}+\left(1+\frac{1}{-\frac{1}{2}-\frac{h}{\sigma_{X}^{2}}+\sqrt{\left(\frac{1}{2}+\frac{h}{\sigma_{X}^{2}}\right)^{2}+\frac{2 r_{X}}{\sigma_{X}^{2}}}}\right) \bar{X} .
$$

Equation (14) has the usual properties. In particular,

- $\frac{\partial \bar{X}}{\partial V^{E E G}}>0$. The higher the expected payoffs from electricity prices, the lower sunk costs are needed to undertake the investment; hence any changes in parameters that increase the value of $V^{E E G}$ (such as rises in $\bar{P}, \sigma, P^{h}, P^{m}, P^{f}$ or a fall in $\kappa$ ), lead to higher thresholds of sunk costs;

- $\frac{\partial \bar{X}}{\partial \sigma_{X}}<0$. The higher the uncertainty about the sunk costs, the lower the thresholds of the sunk costs. In other words, firms postpone the investment decision due to a high level of uncertainty;

- $\frac{\partial \bar{X}}{\partial h}>0$. The higher the cost reduction over time, the lower the sunk costs are needed to undertake the investment.

Modeling the potential benefits from learning and experimentation considerably enriches our modeling set-up. Finally, we can compute the aggregate sunk cost $(\overline{A S C})$ needed to undertake the offshore wind farm investment decision as

$$
\overline{A S C}=C_{0}+\bar{X} .
$$

We can then compare the required $\overline{A S C}$ implied by the model set-up with the actual aggregate sunk cost estimates. In the next subsection, we consider the offshore tender-bidding system. Note that, in this paper, we discuss the sunk costs instead of the revenue flows ("sunk benefits"). This implies that firms should undertake the offshore investment if $\overline{A S C}$ is larger than the estimated market sunk cost. On the contrary, if $\overline{A S C}$ is smaller than the estimated market sunk cost, then the offshore wind farm investment will be put on hold until the market sunk cost drops below $\overline{A S C}$.

\subsection{Offshore Tender Bidding}

As mentioned previously, the offshore wind energy subsidy level is a debated question. The difficulty in setting feed-in tariffs is that if the level is too high, firms will make excessive profits. On the contrary, if it is too low, no deployment of offshore wind energy will take place. A solution to the problem would be to run a tender for new projects, requiring firms to bid for the right to develop a new project. Since the system is designed to reward firms offering to produce offshore wind energy at the lowest cost, most economists start from a parti pris in favor of the tender bidding toolkit. Provided that there is a reasonable number of firms submitting bids, this is an efficient way to allocate the 
projects to the most efficient firms and thus avoid the risk of deadweight losses caused by the feed-in tariff system.

In Denmark, the offshore wind tender process kicked off in 2013. The firm with the best and cheapest plan obtains the permit and grant to develop the wind farm. Recently, the winning tender for the wind farm Horns Rev 3 came from Vattenfall Vindkraft, which agreed a price of $10 \mathrm{ct} / \mathrm{kWh}$ over the next 12 years, which is the period during which the offshore wind farm will receive subsidies. Thereafter, the Horns Rev 3 facility will produce electricity at the market price and will no longer receive any form of subsidy. The winning bid is well below $14 \mathrm{ct} / \mathrm{kWh}$, which is the price in the Anholt Offshore Wind Farm. For the time being, this makes it the cheapest offshore wind farm in Europe. The graphical illustration in Figure 3 clarifies the assumed timeline of the tender-bidding scheme.

Figure 3: Timeline of the Tender-Bidding Scheme

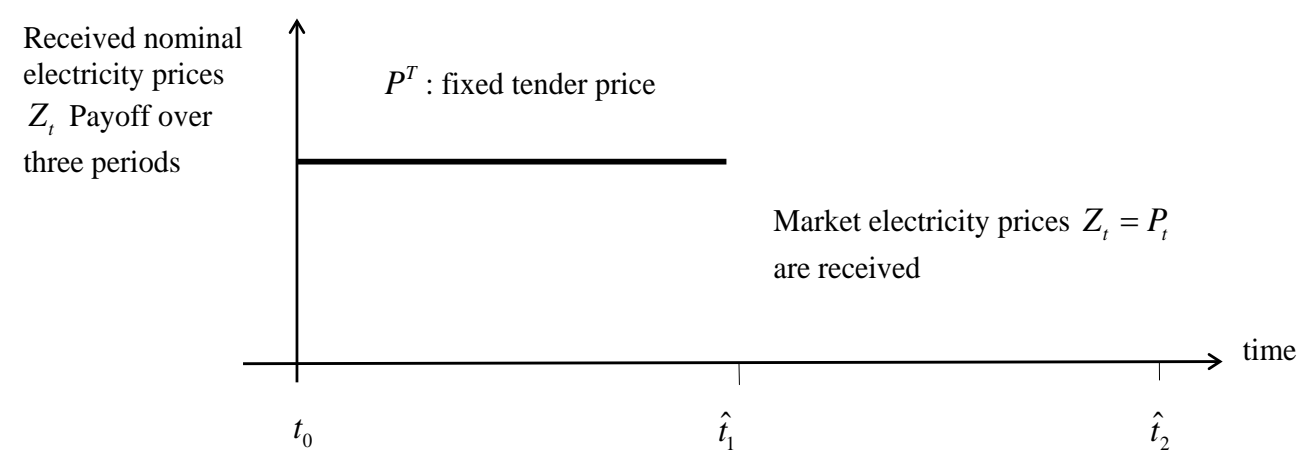

During period $\hat{\tau}_{1} \in\left(t_{0}, \hat{t}_{1}\right)$, the offshore wind farm with the tender bid is guaranteed a fixed electricity price of $P^{T} \mathrm{ct} / \mathrm{kWh}$. In the second operating phase, $\hat{\tau}_{2} \in\left(\hat{t}_{1}, \hat{t}_{2}\right)$, the offshore wind farm receives market electricity prices until the end of the offshore wind farm life, $\hat{t}_{2}$.

With the same mean-reverting electricity prices as in equation (1), we can compute the expected intertemporal payoffs of the tender-bidding scheme $V^{T}$ :

$$
V^{T}\left(P \mid \bar{P}, \sigma, \kappa, P^{T}\right)=A_{0}^{T}+(1-\tau) E_{0}\left[\int_{\hat{t}_{1}}^{\hat{t}_{2}}\left[P_{t} a \bar{y}-\delta \bar{y}\right] e^{-r\left(t-t_{0}\right)} d t\right]
$$

where $A_{0}^{T}$ denotes the intertemporal payoffs from the guaranteed price $P^{T}$ in phase $\hat{\tau}_{1}$ :

$$
A_{0}^{T}=(1-\tau) \int_{t_{0}}^{\hat{t}_{1}}\left[P^{T} a \bar{y}-\delta \bar{y}\right] e^{-r\left(t-t_{0}\right)} d t=\frac{(1-\tau)\left(P^{T} a \bar{y}-\delta \bar{y}\right)\left(1-e^{-r\left(\hat{t}_{1}-t_{0}\right)}\right)}{r+\lambda} .
$$


The integral $(1-\tau) E_{0}\left[\int_{\hat{t}_{1}}^{\hat{t}_{2}}\left[P_{t} a \bar{y}-\delta \bar{y}\right] e^{-r t} d t\right]$ represents the expected intertemporal payoffs from electricity prices in phase $\hat{\tau}_{2}$, and all the other parameters are the same as in the previous section. The rest of the set-up of the tender-bidding scheme is the same as the one of the EEG tariff scheme. The integral of phase $\hat{\tau}_{2}$ can be computed numerically as in the previous section (see the Appendix for computation details). Once the value of $V^{T}$ is obtained, we can then use the real options obtained from the previous section and apply them to the value-matching and smooth-pasting conditions of equations (12) and (13) by substituting $V^{E E G}$ with $V^{T}$ of equation (16). After combination and manipulation, we find that the sunk cost thresholds of the tender-bidding scheme $\bar{X}^{T}$ must satisfy

$$
V^{T}\left(P \mid \bar{P}, \sigma, \kappa, P^{T}\right)=C_{0}+\left(1+\frac{1}{-\frac{1}{2}-\frac{h}{\sigma_{X}^{2}}+\sqrt{\left(\frac{1}{2}+\frac{h}{\sigma_{X}^{2}}\right)^{2}+\frac{2 r_{X}}{\sigma_{X}^{2}}}}\right) \bar{X}^{T} .
$$

The threshold $\bar{X}^{T}$ is found by solving equation (14). Based on this calculation, potential offshore wind farm investors will compare the required aggregate sunk cost $\overline{A S C^{T}}=C_{0}+\bar{X}^{T}$ of the model to the actual sunk costs and reverse engineer the corresponding tender-bidding price $P^{T}$. Thereby, competitive prices will drive down the price of offshore wind energy.

In the next section, we compare the German visions, as laid down in the Energiewende, with the model calibration results. The simulations allow us to inspect the logical soundness of the modeling framework and demonstrate the main insights from the methodology outlined above.

\section{Model Calibration and Evaluation}

This section focuses on the model parameterization, which serves as an input for the numerical analysis. We first calculate the parameters of equation (1). To estimate the parameters of the stochastic process for the electricity price, we use the historical spot prices from the European Energy Exchange (EEX) in Leipzig from 2009 to 2014. We fit the price process to the average monthly data. Using the maximum likelihood method yields a mean-reversion rate $\kappa=3.16$, a risk parameter of $\sigma=0.4366$ and a long-run mean electricity price of $\bar{P}=3.99 \mathrm{ct} / \mathrm{kWh}$.

Next we provide a perspective on the various cost and price elements. The operational life of the investment project is assumed to be $T=25$ years. The offshore wind farm in the model calculations has a capacity of $400 \mathrm{MW}$ and the investment expenditures cost estimate is $3750 \mathrm{EUR} / \mathrm{kW}$ in 2014. Thus, the total construction sunk cost is 1.5 billion EUR. This includes the cost of the wind turbine, the cost of the electrical infrastructure and the cost of logistics and installation, as well as the 
development and engineering costs. The grid connection costs are not included in the analysis, as the German regulation puts the responsibility for the grid connection on the grid operator. ${ }^{12}$ Our valuematching conditions are computed at $t=t_{0}$, which implies that for an offshore wind farm to be finished in 2016-2017 with a spending decision now, the expected sunk cost should be about 1.41 1.45 billion EUR. The median market sunk cost is thus 1.43 billion EUR. Without considering uncertainty and real options, firms should therefore invest when the aggregate sunk costs are below 1.43 billion EUR.

The de-commissioning costs are 175,000 EUR/mW, which yield 70 million for a wind farm with a capacity of $400 \mathrm{~mW}$. This implies that the maximum wind farm electricity output capacity per year $\bar{y}$ is equivalent to 0.035 billion EUR per year for each $P$ cent $/ \mathrm{kWh} .{ }^{13}$ Another major variable influencing the revenue of an offshore wind farm is the real running time of a wind turbine. The technologically and meteorologically determined capacity utilization rate $a$ is assumed to be 0.45 . The above cost assumptions describe the status quo, using state-of-the-art technology. Against the background of the discussion in subsection 2.1, we furthermore assume that the sunk costs will fall by about one-third in the next 8-9 years due to learning by doing. Therefore, we use $C_{0}=0.9$ billion EUR with a cost reduction potential parameter $h=0.06$ and $\sigma_{X}=0.05$.

On the revenue side, we have $P^{h}=19 \mathrm{ct} / \mathrm{kWh}$ for phase $\tau_{1}, P^{m}=15 \mathrm{ct} / \mathrm{kWh}$ for phase $\tau_{2}$ and the floor price $P^{f}=3.5 \mathrm{ct} / \mathrm{kWh}$ for phase $\tau_{3}$, with $t_{0}=0, t_{1}=8, t_{2}=10, t_{3}=20$ and $t_{4}=25$ in the EEG scenario. In the tender-bidding scheme, we assume $P^{T}=12 \mathrm{ct} / \mathrm{kWh}$ within $\hat{t}_{1}=12$ years and $\hat{t}_{2}=13$. Remember that this parameterization is a middle-of-the-road estimate derived from recent Danish tender-bidding schemes. We handle the associated uncertainty by assigning different values in the robustness analysis. The tax rate $\tau$ on profits is assumed to be 0.2 in both regimes. Furthermore, an annual operational cost rate per maximal output $\delta=0.05$ applies. The risk-free rate $r$ to discount future profit streams is assumed to be $0.03 .{ }^{14}$ Likewise, $r_{X}$ is assumed to be 0.10 . To solve the model numerically, we discretize the model into equiwidth time intervals.

It goes without saying that the model calibration leaves ample room for slippage. It is for this reason that we next provide a sensitivity analysis. This is intended to develop an understanding of the robustness of the results. To keep the exposition concise, we focus our calibration exercise on the key parameters. Figure 4 illustrates the numerically calculated thresholds and thus the optimal decision

\footnotetext{
${ }^{12}$ As mentioned previously, these costs depend upon a number of factors, including the water depth, the foundation technology and the distance from the coast. The cost and revenue assumptions are based on expert opinions. A primary data source is Balks and Breloh (2014a, 2014b). For a split of the total investment costs into single categories (turbine, foundation, electrical components, installation, management costs), see Prässler and Schaechterle (2012).

${ }^{13}$ The wind farm is assumed to generate $400 \mathrm{~mW}$ per year. The unit electricity price $P$ is computed by cent $/ \mathrm{kWh}$. Therefore, we have $(P \times 400,000 \times 24 \times 365) / 100=P \times 35,000,000$, which is equivalent to 0.035 billion EUR per year per $P$ cent $/ \mathrm{kWh}$.

${ }^{14}$ Remember that the discount rate is made up out of thin air. We will not explore the impact of varying the discount rate because the intention is to demonstrate the effects of varying those factors that are specific to offshore wind power, rather than entering the debate about the "correct" discount rate.
} 
strategy for varying minimum long-term sunk $\operatorname{cost} C_{0}$. This places direct emphasis on the need for investors, who will typically want to study the investment thresholds. The left (right) panel gives the results for the EEG (tender-bidding) regulatory regime. The analytical model solutions are given with and without real options in each case. The comparison in Figure 4 reveals the relative attractiveness of the offshore investment project across regulatory regimes at a glance. Moreover, a comparison of the dotted, dashed and solid lines indicates that adding uncertainty and option values considerably enriches the analysis. Conversely, one might say that neglecting such features leads to erroneous conclusions.

Figure 4: The ASC Thresholds as a Function of $C_{0}$
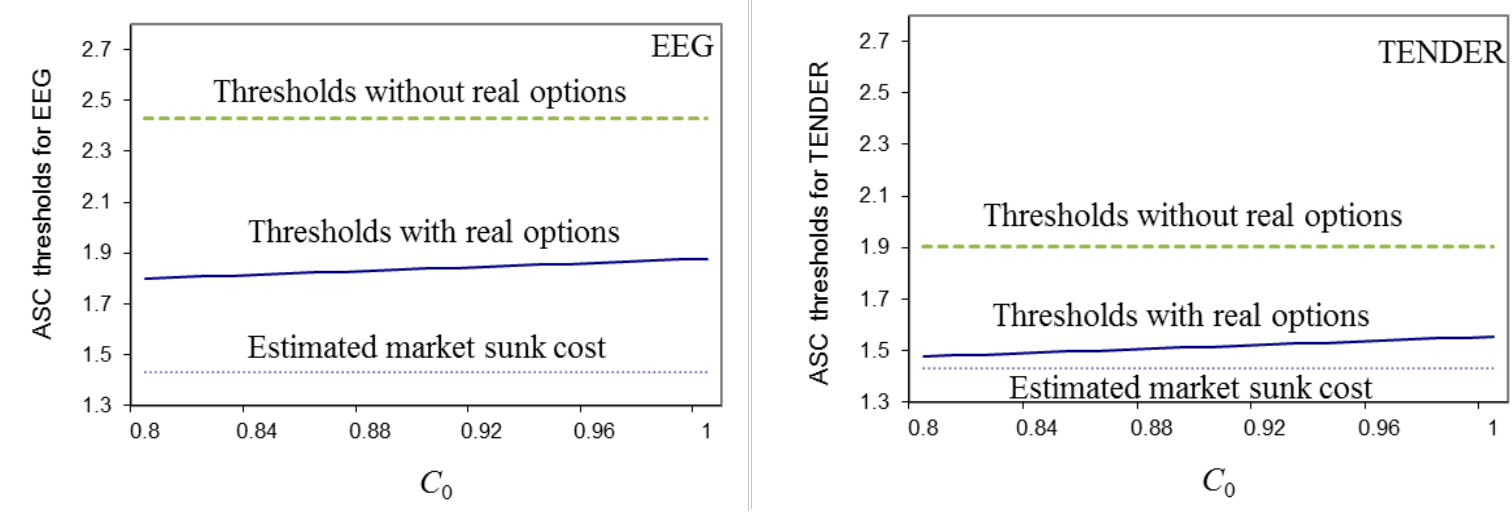

Note that the thresholds are related to the aggregate sunk costs. This means that below the thresholds, firms undertake the investment; above the thresholds, firms do not undertake the investment. As the estimated market sunk cost is 1.43 billion EUR in 2016-2017 prices (dotted line), we can see that both the EEG scheme and the tender scheme attract investors to undertake the off-shore wind farm project over time interval $C_{0} \in[0.8,1.0]$. Note that the sunk cost thresholds without real options (dashed green line) are computed with zero real options values, which implies that the thresholds are just the value of $V^{E E G}$ or $V^{T}$ by the value-matching conditions. The increasing thresholds with real options (solid blue line) are intuitive: a higher constant $C_{0}$ implies smaller uncertain sunk costs and the associated decline in uncertainty encourages firms to invest earlier. Overall, the results indicate that the gains of early investment dominate the benefits of waiting for both regulatory regimes. Consequently, the optimal timing strategy is to invest immediately. The direct comparison of the two regulatory regimes reveals that the current German feed-in tariff system does not expose German project developers to price competition; thus, electricity generation is not achieved at the lowest cost. Put differently, a key takeaway is that the current feed-in tariffs under the EEG 2012 regime constitute 
an inefficient means of energy policy in the context of the real options set-up. This result is consistent with the emerging wisdom among experts. ${ }^{15}$

We next conduct an additional experiment in which we analyze the sensitivity of the ASC thresholds with respect to the real running time of the wind turbines, $a$. To assess the effects of adopting the real options approach, we again investigate the impact of various utilization rates, $a$, upon the $\overline{A S C}$ thresholds for both regulatory regimes. The graphs in Figure 5 also give the traditional market sunk cost.

Figure 5: The ASC Thresholds as a Function of the Running Time of the Wind Turbines $a$
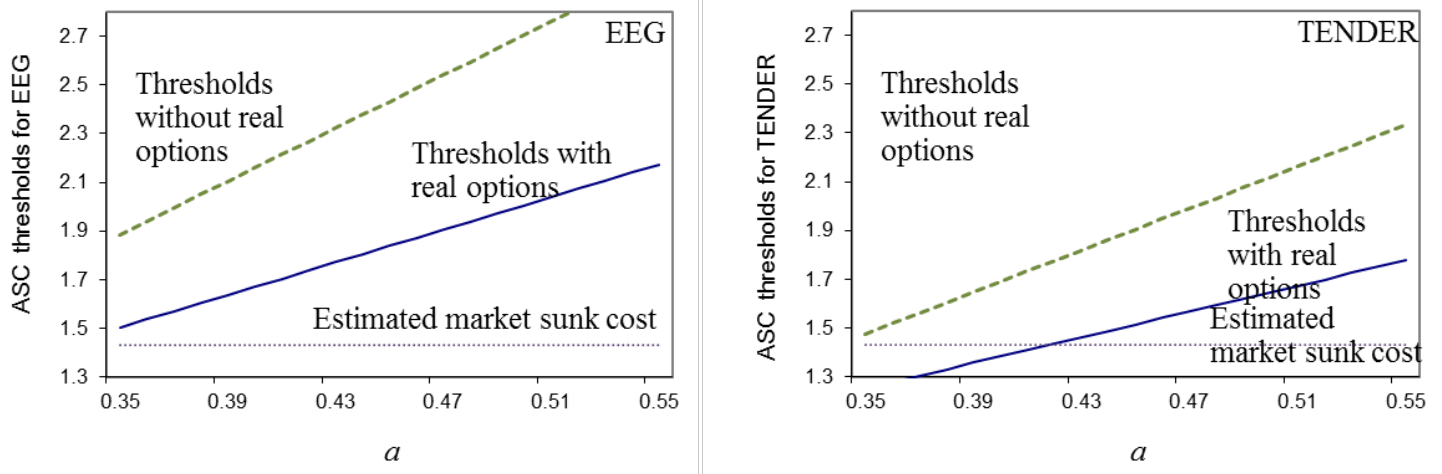

A higher utilization rate $a$ implies an increase in the values of $V^{E E G}$ and $V^{T}$, which is tantamount to a higher incentive for immediate investment. As expected, the ASC thresholds are positively sloped. In other words, a higher real running time of the wind turbines reduces the option value of waiting and thus there is a stronger incentive to invest. The results in the left panel indicate that the EEG subsidy scheme is so generous that firms would enter the market even with very low values of $a$. On the contrary, the right panel indicates that firms will not participate in the offshore tender bidding scheme with $P^{T}=12 \mathrm{ct} / \mathrm{kWh}$ for 12 years if $a$ is expected to be below 0.41 . In light of the above, the German feed-in tariff support scheme is very attractive in terms of profitability.

We take a step further and analyze the sensitivity of the numerical results with respect to varying degrees of learning by doing, $h$. A higher speed of learning by doing implies that the real options are increasing. As both panel in Figure 5 indicate, firms wait longer and only invest at lower aggregate sunk costs. The right panels indicates that firms in the tender-bidding scenario are indifferent to bidding if parameter $h$ is around 8 percent.

\footnotetext{
${ }^{15}$ This is consistent with the KPMG (2010) survey results. KPMG asked market participants to rank European offshore wind markets in relation to the expected returns. The answer was that the UK offers the best conditions, followed by Germany.
} 
Figure 6: The ASC Thresholds as a Function of the Learning-by-Doing Parameter $h$
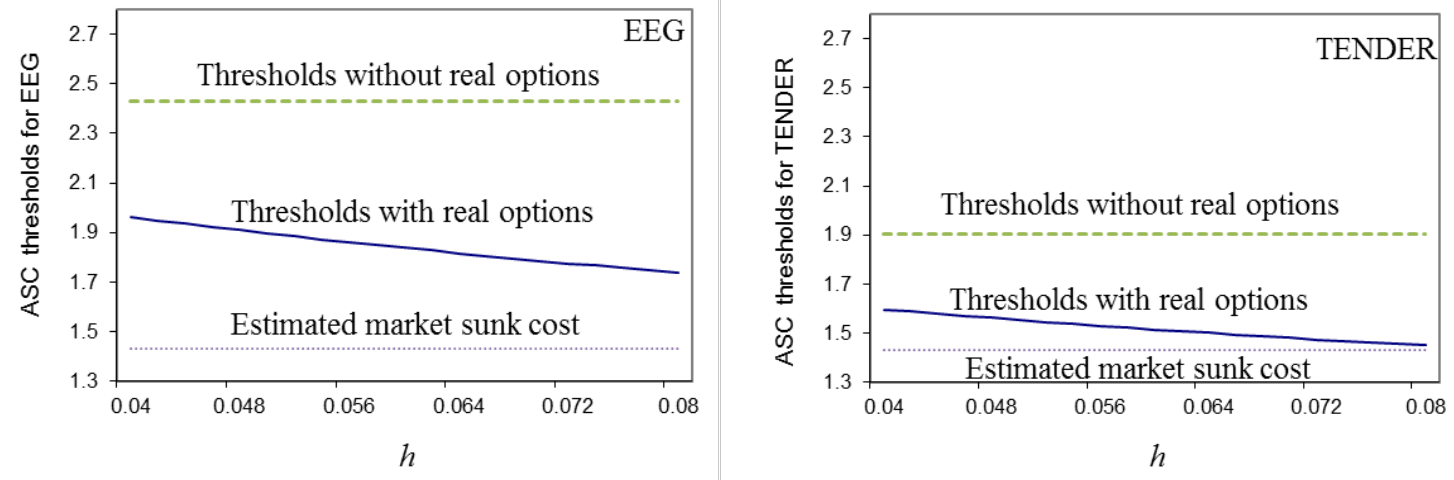

Figure 7: The ASC Thresholds as a Function of the Standard Deviations $\sigma$ and $\sigma_{X}$
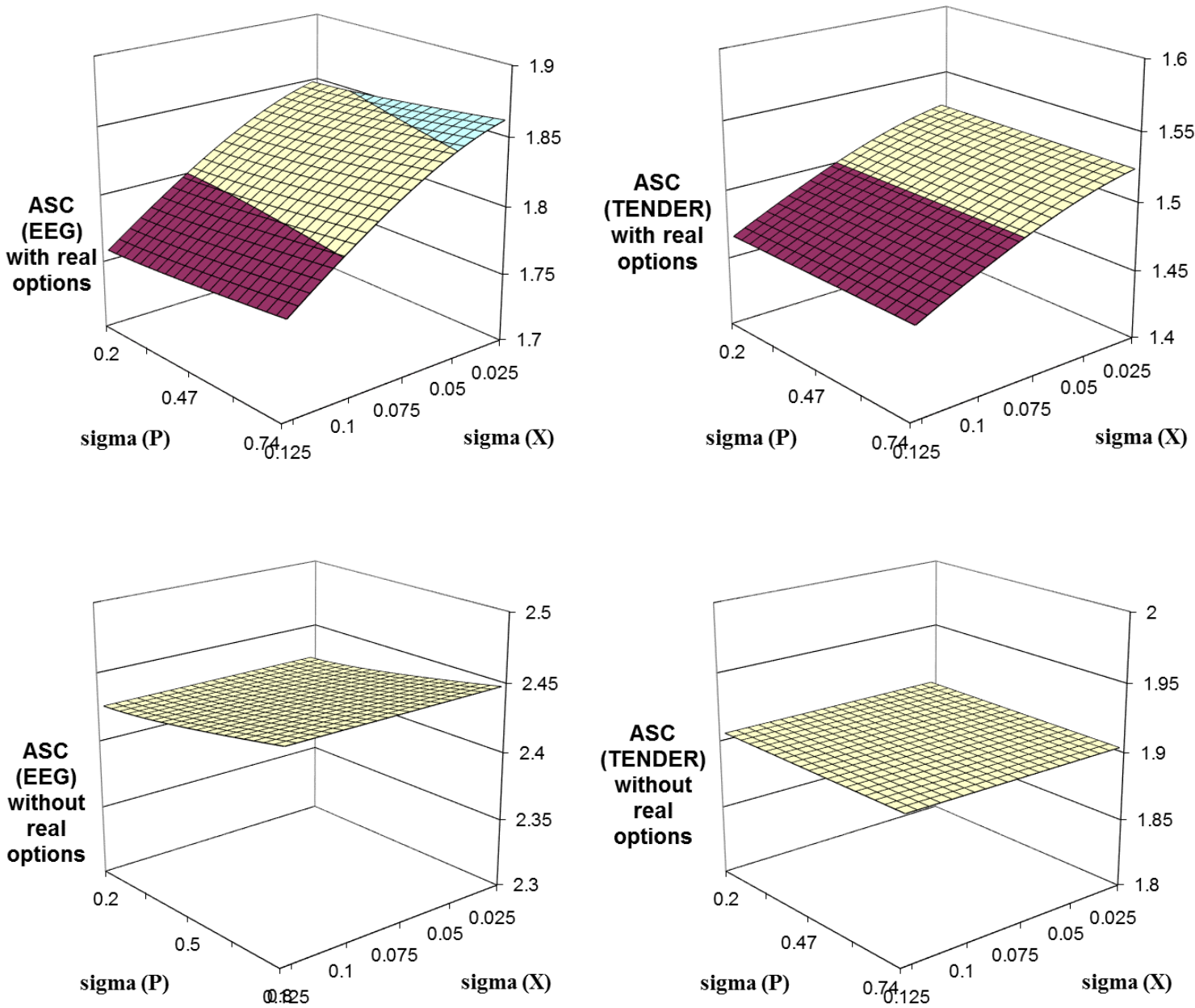

Subsequent to this, we study the effects of price $(\sigma)$ vs sunk cost uncertainty $\left(\sigma_{X}\right)$. The results are displayed in the three-dimensional graphs in Figure 7. As expected, there is electricity price uncertainty in the distant future and thus $\sigma$ has no impact upon the aggregate sunk cost thresholds. 
The mechanism behind the result is simple. The reason is the mean-reverting dynamics of electricity prices. On the contrary, $\sigma_{X}$ increases the ASC thresholds throughout and thus leads to an increase in cautiousness. To summarize, the two subsidy regimes yield remarkably similar policy results. In any case, the thresholds are all greater than the market sunk cost of 1.43 billion and thus firms have an incentive to invest immediately in both regimes.

Finally, we take a step further and highlight the role played by the guaranteed feed-in prices $P^{h}$ and $P^{m}$ in the EEG system and the offered price $P^{T}$ in the tender-bidding system in the investment decision. In Figure 8, we finally simulate the effect of lower electricity prices $P^{h}, P^{m}$ and $P^{T}$, respectively. To simplify the discussion, we assume that the fixed feed-in tariff prices $P^{h}$ and $P^{m}$ are reduced in step. The answer to the question of how declining guaranteed prices affect investment in offshore wind seems to be "it depends." The numerical results indicate that a concurrent decline of $P^{h}$ and $P^{m}$ by more than 34 percent (to less than 66 percent of their guaranteed current level) will lead firms to refrain from participating in the offshore wind farm project. In the tender-bidding scheme, a much smaller decline to 90 percent of the current price level $\left(P^{T}=10.8 \mathrm{ct} / \mathrm{kWh}\right.$ instead of $P^{T}=12$ $\mathrm{ct} / \mathrm{kWh}$ ) will already lead firms to adopt a wait-and-see strategy.

Figure 8 The ASC Thresholds of Declining Prices $P^{h}, P^{m}$ and $P^{T}$ (in \%)
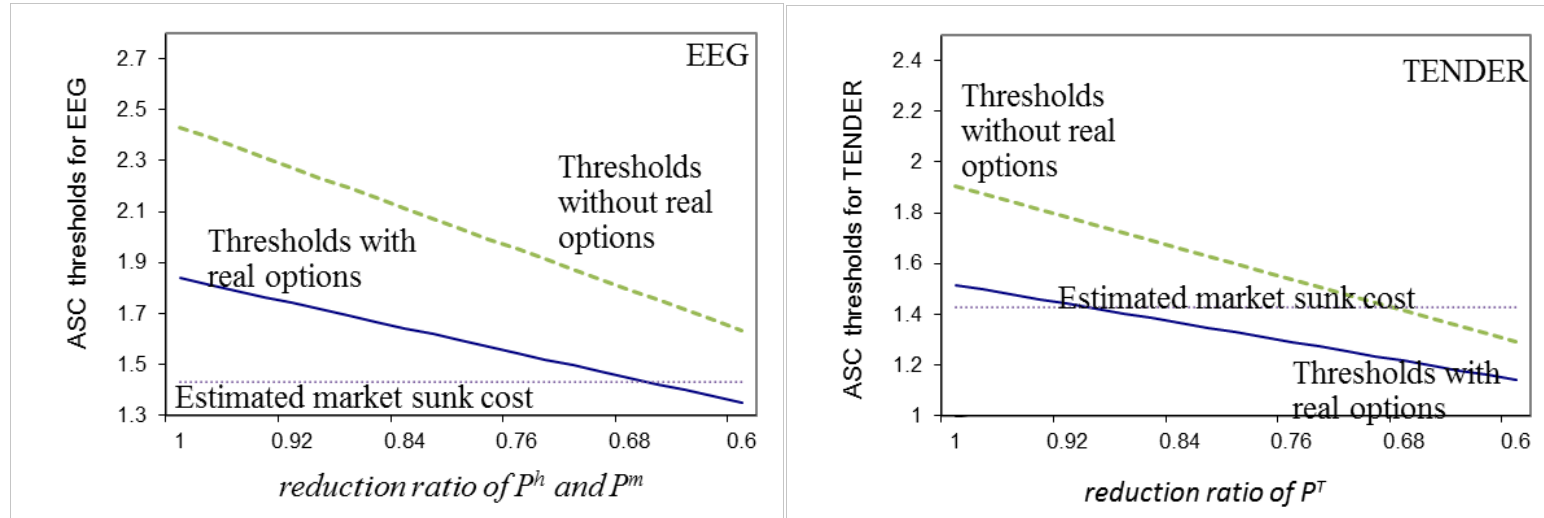

The quintessence is that the existing feed-in tariffs are an inefficient and expensive policy mechanism for promoting offshore wind energy. It is evident that policymakers have to address the balancing act by reconciling as far as possible two opposing demands: the need to provide sufficient support to realize future offshore wind projects whilst at the same time sending a clear signal to the offshore wind industry that costs must fall. Against this background, the numerical results reveal that the lavish long-term EEG subsidies set prices that provide higher returns than needed to secure investment. In other words, the current subsidy system is no coherent solution. For this reason it is clear that the 
current subsidy level should expire. This implies that for Germany the policy question is how to unwind from a period of too-generous feed-in tariffs for offshore wind energy. ${ }^{16}$

In conclusion, the strength of the numerical exercises is to provide a perspective on how parameters change the competitive landscape. Furthermore, the comparison of the feed-in tariff system and the tender-bidding system deepens our understanding of how alternative support schemes determine the financial attractiveness of offshore wind power development and thereby the European offshore wind power market landscape under the European Energy Directive.

\section{Conclusion and Future Directions}

Given the ambitious renewable energy targets, offshore wind commands widespread support and is in a strong political position despite its alleged expensiveness for consumers. Against this background, this paper strived to contribute theoretically sound perspectives to the offshore wind discussion. We examined the issue in the following sequence. In the first part, we developed a real options modeling framework. An extensive calibration exercise then followed. ${ }^{17}$

In the interest of brevity, we focused our analysis on two alternative subsidy schemes. The key tool for this assessment was a real options modeling framework. We believe that real options models provide a rigorous modeling framework in which to examine investment incentives under uncertainty and help energy firms to manage investment risk better. We scrutinized the incentives of the current EEG feed-in regulation for investing in offshore wind farms as well as an alternative tender-bidding scheme. The stochastic modeling set-up presented above tells the story in a logically coherent way and is able to provide the numerical solutions to the story. Although the real options framework is far from being the deus ex-machina, the modeling approach provides several new insights into the impact of the EEG 2012 feed-in tariffs on offshore wind farm investments in Germany and guides our thinking about appropriate policy design. In terms of policy implications, two points can be made. First, a shift from interventionist policy measures towards more market-based instruments is a particular priority. Second, the renewable offshore wind sector should be subject to competition and the guaranteed prices should be phased out.

It is fair to acknowledge that the results of this real options proof-of-concept study hinge on a number of modelling assumptions that impose caveats and point to potential future improvements. In this context it should be noted that we have neglected policy uncertainty. In the first two sections, the two subsidy scenarios were treated as independent from one another. On closer inspection, however, it is

\footnotetext{
${ }^{16}$ The nuanced conclusion on the impact of the EEG 2012 feed-in tariff system that we obtain in this paper contrasts sharply with the almost universal belief that the incorporated subsidy level is necessary to trigger investment in offshore energy. The good news is that the high EEG subsidy level is largely an artificial problem. The bad news is that that does not make it a solvable one. Redressing the existing subsidies is among the most politically fraught of policy issues since those exposed to competition will organize themselves in opposition.

${ }^{17}$ The modeling set-up is quite flexible; therefore, it is readily conducive to incorporating alternative price and cost processes or even further uncertainties.
} 
clear that they are intertwined and smart models should not treat them in isolation. Recognizing that at the time of making investment decisions agents may have information about future policy changes to occur with non-zero likelihood, it is realistic to assume that these regime changes which may or may not materialize in the end, influence the current investment behavior of agents. Therefore, the crucial next modeling step is to augment the current EEG feed-in tariff system with future policy uncertainty. Projecting the future by merely extending the past is rarely adequate, especially when the underlying policies are expected to be turned upside down. Rather, current investment decisions depend on the likelihood of anticipated policy changes. On the one hand, the extension of EEG 2012 that already occurred in the year 2014 provides an argument for another possible extension in the future. On the other hand, the most recent revision of the EEG already envisages a longer-term transformation away from feed-in tariffs and towards tender schemes on some indefinite future date. However, these schemes still have to be drafted, meaning that everything is still up in the air. Anticipated discreet changes in the market design can be accounted for with a just once jump/drop Poisson distribution modeling approach in which a policy change in the future is anticipated to occur but the timing is uncertain. Different pathways that German policy makers might choose to adopt, may be represented by different jump probabilities and jump sizes. This approach provides a compact presentation of future policy uncertainty and points to potentially fruitful future research.

Our partial-equilibrium modeling set-up also does not address issues related to competitive interactions in the offshore wind industry. In a competitive industry firms have an incentive to act quickly to gain strategic advantages over their competitors. Based on a duopolistic real options game, several studies have demonstrated how competitive dynamics affect the timing of new technology adoption. $^{18}$

In conclusion, the presented model and the thorough numerical exercises contribute to the literature by deepening our understanding of the impact of various offshore wind support schemes. These findings can serve as guidance for academics, policymakers and practitioners alike.

\footnotetext{
${ }^{18}$ See, for example, Huisman and Kort (2003, 2004). Leahy (1993) showed that the assumption of myopic firms that ignore the impact of other firms' actions results in the same critical boundaries that trigger investment as a model in which firms correctly anticipate the strategies of other firms. Grenadier (2002) recently extended Leahy's (1993) "Principle of Optimality of Myopic Behavior" to the apparently more complex case of dynamic oligopoly under uncertainty. Therefore, we ignored the behavioral assumptions regarding market rivalry.
} 


\section{References:}

Acemoglu, D., Akcigit, U., Hanley, D. and W.R. Kerr (2014) "Transition to Clean Technology", NBER Working Paper No. 20743, Cambridge (Mass.).

Balks, M. and P. Breloh (2014a) "Risikobewertung bei Investitionen in Offshore-Windanlagen" Wirtschaftsdienst 94, Issue 1, 26-33.

Balks, M. and P. Breloh (2014b) "Auswirkungen des neuen Erneuerbare-Energien-Gesetzes auf Offshore-Wind-Investitionen”, Wirtschaftsdienst 94, Issue 7, 520-523.

Boomsma, T.K., Meade, N. and S.-E. Fleten (2012) "Renewable Energy Investments under Different Support Schemes: A Real Option Approach”, European Journal of Operational Research 220, 225237.

Cartea, A. and M. Figueroa (2005) "Pricing in Electricity Markets: A Mean Reverting Jump Diffusion Model with Seasonality", Applied Mathematical Finance 12, 313-335.

Dixit, A. and R. Pindyck (1994) Investment under Uncertainty, Princeton (Princeton University Press).

Green, R. and N. Vasilakos (2011) “The Economics of Offshore Wind”, Energy Policy 39, 496-502.

Grenadier, S.R. (2002) "Option Exercise Games: An Application to the Equilibrium Investment Strategies of Firms”, Review of Financial Studies 15, 691-721.

Hlouskova, J., Kossmeier, S., Obersteiner, M. and A. Schnabl (2005) "Real Options and the Value of Generation Capacity in the German Electricity Market”, Review of Financial Economics 14, 297-310.

Huisman, K. and P. Kort (2003) "Strategic Investment in Technology Innovations", European Journal of Operations Research 144, 209-223.

Huisman, K. and P. Kort (2004) "Strategic Technology Adoption Taking into Account Future Technological Improvements: A Real Options Approach”, European Journal of Operations Research 159, 705-728.

Jongbloed, R.H., van der Wal, J.T. and H.J. Lindeboom (2014) “Identifying Space for Offshore Wind Energy in the North Sea. Consequences of Scenario Calculations for Interactions with Other Marine Uses”, Energy Policy 68, 320-333.

Kitzing, L., Mitchell, C. and P. Mothorst (2012) "Renewable Energy Policies in Europe: Converging or Diverging?”, Energy Policy 51, 192-201.

KPMG (2010) Offshore Wind Europe - 2010 Market Report, London.

Leahy, J. (1993) “Investment in Competitive Equilibrium: The Optimality of Myopic Behaviour”, Quarterly Journal of Economics 108, 1105-1133.

Prässler, T. and J. Schaechterle (2012) "Comparison of the Financial Attractiveness among Prospective Offshore Wind Parks in Selected European Countries”, Energy Policy 45, 86-101.

Rodrik, D. (2014) “Green Industrial Policy”, Oxford Review of Economic Policy 30, 469-491.

Stokey, N.L. (2009) The Economics of Inaction - Stochastic Control Models with Fixed Costs. Princeton (Princeton University Press). 
Schwartz, E.S. and E.S. Smith (2000) "Short-Term Variations and Long-Term Dynamics in Commodity Prices”, Management Science 46, 893-911.

\section{Appendix: Computing the Particular Integrals for the Floor Price in the Operation Phases $\tau_{3}$ and $\tau_{4}$}

Using $=\ln \frac{P}{\bar{P}}$, equation (1) in the main text can be rewritten as

$$
d x=-\kappa x d t+\sigma d W
$$

where the new mean is normalized to $\ln (1)=0$. Thus, the substitution leaves us with the well-known Ornstein-Uhlenbeck process. An analogous derivation for $Z_{t}=\max \left(P_{t}, P^{f}\right)$ in the third wind farm operation phase yields

$$
Z_{t}=\left\{\begin{array}{l}
P_{t}, \text { for } P_{t}>P^{f} \\
P^{f}, \text { for } P_{t} \leq P^{f}
\end{array}\right.
$$

Taking logs on both sides of (A2) and normalizing $P^{f}$ leaves us with

$$
\ln \frac{Z_{t}}{\bar{P}}=\left\{\begin{array}{l}
\ln \frac{P_{t}}{\bar{P}}, \text { for } \ln \frac{P_{t}}{\bar{P}}>\ln \frac{P^{f}}{\bar{P}} \\
\ln \frac{P^{f}}{\bar{P}}, \text { for } \ln \frac{P_{t}}{\bar{P}} \leq \ln \frac{P^{f}}{\bar{P}} .
\end{array}\right.
$$

We need to transform (A3) in terms of $x=\ln \frac{P}{\bar{P}}$. Substituting $x=\ln \frac{P}{\bar{P}}$ into (A3) yields

$$
\ln \frac{Z_{t}}{\bar{P}}=\left\{\begin{array}{c}
x_{t}, \text { for } x_{t}>\ln \frac{P^{f}}{\bar{P}} \\
\ln \frac{P^{f}}{\bar{P}}, \text { for } x_{t} \leq \ln \frac{P^{f}}{\bar{P}}
\end{array}\right.
$$

The Ornstein-Uhlenbeck process of equation (A1) for $x_{t}$ is well known to have the probability density function

$$
f(z, s)=\sqrt{\frac{\kappa}{\pi \sigma^{2}\left(1-e^{-2 \kappa s}\right)}} e^{-\frac{\kappa}{\sigma^{2}}\left[\frac{\left(z-z_{0} e^{-\kappa s}\right)^{2}}{1-e^{-2 \kappa s}}\right]} .
$$

It is evident that the term $z_{0} e^{-\kappa s}$ of equation (A5) implies that the current value of $z$ and hence the electricity price $P$ has near zero impacts on the pdf for large $\kappa$ and $s$. For example, using $s=$ 10 and $\kappa=3.16$ from the main text, we have $z_{0} e^{-\kappa s}=z_{0} e^{-3.16 \times 10}=\ln \frac{P}{\bar{P}} \times 1.910^{-014} \cong 0$. In other words, the current electricity prices $P$ has no long-run impacts on the values of $V^{E E G}$ and $V^{T}$ of the tender-bidding scheme. For this reason, it was considered appropriate to assume that the electricity price $P$ should have no impact on real options. Through some rearrangement and manipulation, the expectation of $\ln \frac{Z_{t}}{\bar{P}_{t}}$ can be computed as

$$
E\left[\ln \frac{Z_{t}}{\bar{P}}\right]=\ln \frac{P^{f}}{\bar{P}} \int_{-\infty}^{\ln \frac{P^{f}}{\bar{P}}} \sqrt{\frac{\kappa}{\pi \sigma^{2}\left(1-e^{-2 \kappa s}\right)}} e^{-\frac{\kappa}{\sigma^{2}}\left[\frac{\left(x-x_{0} e^{-\kappa s}\right)^{2}}{1-e^{-2 \kappa s}}\right]} d x
$$




$$
+\int_{\ln \frac{P^{f}}{\bar{P}}}^{\infty} x \sqrt{\frac{\kappa}{\pi \sigma^{2}\left(1-e^{-2 \kappa s}\right)}} e^{-\frac{\kappa}{\sigma^{2}}\left[\frac{\left(x-x_{0} e^{-\kappa s}\right)^{2}}{1-e^{-2 \kappa s}}\right]} d x
$$

which can be solved numerically. Solving for $E\left[Z_{t}\right]$ yields

$$
E\left[Z_{t}\right] \cong \bar{P}_{t} e^{E\left[\ln \frac{Z_{t}}{\bar{P}}\right]}
$$

Equation (A7) is somewhat informal. Note that this is an approximate solution as the exponential terms are on expected values, not directly on the stochastic process. Substituting equation (A7) into the term

$$
(1-\tau) E_{0}\left[\int_{t_{2}}^{t_{3}}\left[\max \left(P_{t}, P^{f}\right) a \bar{y}-\delta \bar{y}\right] e^{-r\left(t-t_{0}\right)} d t\right]
$$

of equation (3) in the text finally allows us to obtain the intertemporal values for phase $\tau_{3}$ numerically.

To compute the expected values of $x_{t}=\ln \frac{P_{t}}{\bar{P}}$ in phase $\tau_{4}$, we can just take the expected value from (A5) and directly integrate from $x=-\infty$ to $x=\infty$. This yields

$$
E\left[\ln \frac{Z_{t}}{\bar{P}}\right]=\int_{-\infty}^{\infty} x \sqrt{\frac{\kappa}{\pi \sigma^{2}\left(1-e^{-2 \kappa s}\right)}} e^{-\frac{\kappa}{\sigma^{2}}\left[\frac{\left(x-x_{0} e^{-\kappa s}\right)^{2}}{1-e^{-2 \kappa s}}\right]} d x .
$$

Using the equation

$$
E\left[P_{t}\right] \cong \bar{P}_{t} e^{E\left[\ln \frac{P_{t}}{\bar{P}}\right]}
$$

finally permits us to compute the term

$$
(1-\tau) E_{0}\left[\int_{t_{3}}^{t_{4}}\left[P_{t} a \bar{y}-\delta \bar{y}\right] e^{-r\left(t-t_{0}\right)} d t\right]
$$

for the expected payoffs for phase $\tau_{4}$. 